BERKALA FISIKA INDONESIA

Jurnal IImiah Fisika, Pembelajaran dan Aplikasinya

http://journal.uad.ac.id/index.php/BFl/index 2085-0409 (Print) | 2550-0465 (online)

\title{
Analisis kesalahan siswa dalam menyelesaikan soal-soal fisika pada materi elastisitas bahan kelas XI IPA SMA muhammadiyah Maumere
}

\author{
Kataria Inus ${ }^{1 *}$, Erwin Prasetyo ${ }^{2}$, Florentinus Primarius Naraama Koten ${ }^{3}$, Pujianti Bejahida \\ Donuata 4 \\ 1,2,3,4 Pendidikan Fisika, Institut Keguruan dan IImu Pendidikan Muhammadiyah Maumere, Indonesia \\ Email: risnachatrynwell@gmail.com* \\ * Penulis korespondensi
}

\begin{tabular}{l}
\hline Informasi artikel \\
\hline Sejarah artikel: \\
Dikirim \\
Revisi \\
Diterima \\
\hline
\end{tabular}

\section{Kata kunci:}

Analisis kesalahan siswa

Kesalahan memahami

Kesalahan transformasi

Kesalahan keterampilan proses

Kesalahan pengkodean

\section{Keywords:}

Analysis of student errors

Comprehension Errors

Transformation Errors

Process Skill Errors

Encoding Errors

\begin{abstract}
ABSTRAK
Tujuan penelitian ini adalah untuk mengetahui pola dan penyebab kesalahan siswa dalam menyelesaikan soal-soal fisika pada materi elastisitas bahan. Subjek penelitian ini adalah siswa kelas XI IPA SMA Muhammadiyah Maumere yang berjumlah 27 orang. Pemilihan subyek penelitian didasarkan pada penilaian urutan hasil tes siswa yang melakukan kesalahan. Dua siswa dari kelompok atas, dua siswa dari kelompok tengah, dan dua siswa dari kelompok bawah bertindak sebagai peserta pembelajaran. Enam subyek dipilih berdasarkan rangking jumlah kesalahan dari tiap kelompoknya. Kemudian 6 subyek dilakukan wawancara secara intensif. Hasil penelitian mengungkapkan bahwa siswa melakukan kesalahan dalam memahami, transformasi, keterampilan pemrosesan, dan menulis. Kesalahan transformasi adalah yang paling umum dari empat jenis kesalahan yang dibuat oleh siswa. Kesalahan ini disebabkan oleh siswa kurang memahami konten soal elastisitas bahan dan langkah-langkah dalam menyelesakan soal.
\end{abstract}

This is an open access article under the CC-BY-SA license

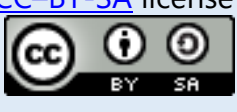

\begin{abstract}
An Analysis of Student's Errors in Completing Physics Questions on Elasticity Material in Grade XI IPA at SMA Muhammadiyah Maumere. This study aimed to determine the patterns and causes of students' errors in solving physics problems on the material elasticity of materials. The subjects of this study were 27 students of class XI IPA SMA Muhammadiyah Maumere. Taking research subjects was based on the ranking of students who made mistakes from the test results. The research subjects consisted of 2 students from the upper group, 2 students from the middle group, and 2 students from the lower group. Six subjects were selected based on the ranking of errors in each group. Then 6 subjects were interviewed intensively. The results showed that students' mistakes were in the form of misunderstanding, transformation errors, processing skills errors, and writing errors. Of the four types of errors most students made were transformation errors. This error was caused by students not understanding the content of the material's elasticity and the steps in solving the questions.
\end{abstract}

\section{How to Cite:}

Inus, K., Prasetyo, E., Koten, F. P. N., \& Donuata, P. B. (2020). Analisis kesalahan siswa dalam menyelesaikan soal-soal fisika pada materi elastisitas bahan kelas XI IPA SMA muhammadiyah maumere. Berkala Fisika Indonesia: Jurnal Ilmiah Fisika, Pembelajaran dan Aplikasinya, 11(2), 53-58. 


\section{Pendahuluan}

Fisika adalah disiplin ilmu yang meneliti fenomena alam (Mulia, 2019). Karena fenomena alam tertentu dapat diinterpretasikan dengan menggunakan filsafat fisika. Fisika dapat dianggap sebagai topik penelitian yang diperlukan. Untuk memperoleh prestasi akademik dalam fisika, siswa harus mempertimbangkan prinsip-prinsip fisika dan menerapkannya dalam latihan pemecahan masalah fisika (Ahliha et al., 2017). Pencapaian hasil belajar merupakan prediktor keberhasilan pembelajaran. Karena banyaknya rumus dan persamaan, pelajaran fisika seringkali dianggap rumit. Menurut Suparno (2009), beberapa siswa SMA tidak menyukai fisika dan tidak menekuninya karena menakutkan, sulit dipahami, dan membutuhkan banyak perhitungan dan rumus. Berdasarkan pandangan para ahli, dapat disimpulkan bahwa fisika merupakan topik yang menakutkan karena mengandung banyak rumus sehingga sebagian siswa tidak menyukai mata pelajaran fisika.

Di Nusa Tenggara Timur (NTT), angka kelulusan Ujian Nasional (UN) baru 47,92\%. Ini merupakan tingkat kelulusan terendah di antara 33 provinsi di Indonesia (Seo, 2010). Penurunan persentase kelulusan ini, menurut Thobias Uly selaku kepala Dinas Pendidikan dan Olahraga disebabkan kurangnya persiapan siswa mengikuti ujian nasional, dan Sumber Daya Manusia (SDM) guru yang seluruhnya belum disertifikasi. Penyebab lainnya yakni masih rendahnya penguasaan kurikulum. Oleh karena itu, kita bisa melihat persentase kelulusan UN di Kabupaten Sikka pada saat ini masih di bawah standar dimana Kabupaten Sikka masih termasuk daerah tertinggal.

Berdasarkan hasil observasi di SMA Muhammadyiah Maumere, nilai UN juga masih standar. Banyak siswa yang belum bisa mencapai $100 \%$ dalam menyelesaikan soal-soal dengan baik dan benar. Maka dari hasil pengamatan di sekolah tersebut, peneliti menemukan banyak kesalahan yang dilakukan siswa dalam mengerjakan soal, baik itu kesalahan konsep maupun kesalahan dalam mengerjakan soal. Seperti yang diketahui bahwa kesalahan yang dilakukan oleh siswa tersebut disebabkan oleh dua faktor yaitu faktor dari dalam dan faktor dari luar diri siswa (Sari et al., 2013). Motivasi, minat dan keterampilan siswa semuanya merupakan pengaruh internal. Sementara itu, lingkungan cuaca, keluarga, siswa, teman sebaya, dan materi pembelajaran semuanya merupakan pengaruh eksternal. Akibatnya, penyebab kesalahan siswa dalam menjawab pertanyaan tersebut harus digali lebih jauh untuk meningkatkan proses pembelajaran dan meningkatkan hasil belajar.

Empat studi yang relevan: 1. Letuna (2011) melakukan penelitian dengan menggunakan sampel kelas X-B dari 25 siswa di SMA Kristen Manekto Strongnana di wilayah Timor Tengah Selatan. Tekanan pada benda padat, cair, dan gas menjadi pokok bahasan penelitian ini. Penelitian ini menemukan dua jenis kesalahan: mitos dan kesalahan dalam penerjemahan kueri. 2) Dalam analisisnya terhadap 100 siswa kelas empat di Assam, India, Jha (2012) menemukan bahwa siswa menemukan lebih banyak kesalahan dalam pemecahan masalah dan keterampilan transformasi. 3). Berdasarkan temuan penelitian di Malaysia dan Australia, Clements dan Ellerton (1996) menyimpulkan bahwa kesalahan paling umum 
yang dilakukan siswa dalam menyelesaikan masalah cerita terjadi pada tahap mengetahui sifat masalah (pemahaman), transformasi, keterampilan metode, dan kecerobohan.

Berdasarkan uraian sebelumnya, maka penelitian ini bertujuan untuk mengetahui pola kesalahan siswa dalam menyelesaikan masalah fisika pada materi elastisitas dan mengetahui mengapa siswa melakukan kesalahan dalam menyelesaikan masalah elastisitas.

\section{Metode}

Jenis penelitian ini adalah penelitian deskriptif kualitatif (Kim et al., 2017). Penelitian ini dilakukan di SMA Muhammadiyah Maumere Tahun Ajaran 2018/2019. Penelitian dilaksanakan dari tanggal 25 Februari sampai 25 Maret. Subjek dalam penelitian ini adalah kelas XI IPA dengan jumlah siswa sebanyak 27 orang. Penelitian ini menggunakan metode kualitatif yaitu observasi, wawancara, atau telaah dokumen. Pemilihan topik studi didasarkan pada sistem penilaian yang menggunakan nilai tes untuk menilai siswa mana yang melakukan kesalahan. Dua siswa dari kelompok atas, dua siswa dari kelompok tengah, dan dua siswa dari kelompok bawah dengan kesalahan terbanyak bertindak sebagai subjek penelitian. Jumlah subjek penelitian sebanyak enam orang siswa, yang selanjutnya akan dilakukan wawancara intensif.

Metode tes dan wawancara digunakan untuk mengumpulkan data. Tujuan dari penyelenggaraan tes ini adalah untuk mengumpulkan data dan informasi untuk kesimpulan tentang kesalahan siswa dalam pemecahan masalah fisika. Soal tes berupa definisi soal tes uraian elastisitas bahan. Wawancara bertujuan untuk mengungkap dan mencatat semua fakta dan topik penelitian yang relevan. Pertanyaan tes wawancara dilakukan bersama-sama. Setiap anak mendapat pertanyaan yang berbeda karena peneliti memeriksa pertanyaan yang menurut peneliti masih banyak siswa yang salah, sehingga peneliti menganalisis jawaban yang salah yang masih banyak dibuat oleh siswa.

\section{Hasil dan Pembahasan}

Hasil penelitian diperoleh setelah peneliti melakukan penelitian pada siswa kelas XI IPA SMA Muhammadiyah Maumere Kabupaten Sikka dengan jumlah siswa 27 orang. Penelitian ini bertujuan untuk mengetahui jenis kesalahan yang dilakukan siswa dan faktor-faktor penyebabnya. Agar penelitian berjalan dengan baik dan sesuai prosedur, peneliti telah mempersiapkan data yaitu soal uraian dengan jumlah soal 5 nomor dimana soal tersebut sudah divalidasi oleh dosen dan guru mata pelajaran fisika. Soal tersebut dibagikan kepada siswa. Sebelum soal tersebut diberikan peneliti mengulangi sedikit materi tetang elastisitas bahan. Setelah peneliti memberikan tes kepada siswa, peneliti langsung melakukan pemeriksaan jawaban dari soal yang diberikan. Dari hasil tes peneliti mengambil sampel untuk melakukan penelitian, dimana peneliti melihat dari siswa yang memiliki kemampuan tinggi, kemampuan sedang, dan kemampuan rendah. Pengambilan sampel tersebut terdiri dari kelompok kemampuan atas Responden 1 (S1), Responden 2 (S2), kelompok kemampuan tengah 
Responden 3 (S3), Responden 4 (S4), dan kelompok kemampuan bawah Responden 5 (S5), Responden 6 (S6).

Tahap awal dalam penelitian, peneliti terlebih dahulu memberikan soal-soal umum pada materi elatisitas bahan yang telah dipelajari sebelumnya oleh siswa dan soal tersebut adalah soal yang sudah divalidasi, hal ini bertujuan untuk mengetahui kemampuan-kemampuan siswa yang telah dibagi dalam beberapa kelompok. Kelompok-kelompok tersebut yaitu kelompok atas terdiri dari dua orang siswa, kelompok sedang terdiri dua orang siswa dan kelompok bawah terdiri dari dua orang siswa.

Peneliti mengajukan pertanyaan deskriptif pada tingkat kedua, berjumlah lima. Pertanyaan didasarkan pada materi yang diajarkan kepada siswa oleh instruktur mata pelajaran. Dalam empat tahun terakhir, pemecah masalah telah menggunakan masalah UN yang telah divalidasi oleh para ahli. Tes ini memakan waktu 120 menit. Pengaturan dan pemantauan dilakukan selama pelatihan untuk mengurangi risiko kecurangan. Peneliti memeriksa tanggapan siswa setelah tugas diselesaikan untuk melihat apakah mereka melakukan kesalahan.

Pada tahap ketiga, peneliti melakukan wawancara tidak terstruktur dengan enam siswa yang telah ditugaskan ke salah satu kelas tergantung pada tingkat keahlian mereka. Kesalahan siswa meliputi:

- Kesalahan pengambilan tes.

- Perbedaan jenis kesalahan joki ujian.

- Kurangnya keterbukaan dan kefasihan dalam komunikasi verbal.

Wawancara ini bertujuan untuk mengetahui faktor-faktor apa saja yang menyebabkan siswa melakukan kesalahan saat menyelesaikan masalah yang menyangkut materi elastisitas dan dokumentasi yang digunakan untuk menguraikan temuan wawancara.

Analisis kesalahan yang dilakukan oleh mahasiswa S1, S4, S5, S6 membuat tiga jenis kesalahan. Sedangkan mahasiswa S2 dan S3 masing-masing melakukan dua jenis kesalahan. Jenis-jenis kesalahan yang dilakukan siswa dalam menyelesaikan materi elastisitas dan penyebab-penyebab terjadinya kesalahan dapat dilihat berdasarkan hasil penilaian, wawancara, dan dokumentasi yang dilakukan terhadap siswa. Subyek penelitian S1, berkemampuan tinggi, memiliki kesalahan dalam memahami masalah (Comprehension Errors) pada soal nomor 5. Pada kesalahan jenis transformasi (Transformation Errors), Subyek ini melakukan 11 kesalahan pada soal nomor 2. Subyek penelitian S2, berkemampuan tinggi, melakukan kesalahan pada nomor 4. Subyek penelitian S3, berkemampuan sedang, melakukan kesalahan pada soal nomor 2 dan 5. Subyek penelitian S4, berkemampuan sedang, melakukan kesalahan pada nomor 2 dan 4. Subyek penelitian S5, berkemampuan rendah, melakukan kesalahan pada soal nomor 4. Subyek penelitian $\$ 6$, berkemempuan rendah, melakukan kesalahan pada soal 1, 4 dan 5 .

Pada kesalahan keterampilan proses (Process Skill Errors) siswa melakukan 4 kesalahan yaitu subjek penelitian S1, berkemampuan tinggi, melakukan kesalahan pada soal nomor 4. Subjek S2, 
berkemampuan tinggi, melakukan kesalahan pada soal nomor 1 . Subjek S4, berkemampuan sedang, melakukan kesalahan pada soal nomor 5. Subjek S5, berkemampuan rendah, melakukan kesalahan pada soal nomor 1. Pada kesalahan penulisan (Encoding Errors), siswa melakukan 1 kesalahan yaitu subjek S5, berkemampuan rendah, melakukan kesalahan pada nomor 5 .

Ada beberapa jenis kesalahan yang dilakukan oleh siswa, termasuk kesalahan transformasi karena mereka tidak memahami kualitas materi soal mengenai hambatan elastisitas dan langkah-langkah dalam menjawab pertanyaan. Hal ini dapat dilihat dari jawaban siswa yang sebagian besar memilih untuk tidak mematuhi protokol dan tidak menanggapi pertanyaan apa pun. Instruktur harus menanyakan lebih banyak pertanyaan tentang elastisitas materi. Siswa harus mengulang lebih banyak materi dan menjawab soal elastisitas materi di rumah agar siap dan mampu menyelesaikan soal elastisitas. Fitri (2007) menemukan beberapa kesalahan, yaitu: (1). Kesalahan menuliskan apa yang diketahui dan ditanyakan tentang soal-soal tersebut ke dalam simbol fisika, (2). Kesalahan dalam memahami konteks masalah, (3). Kesalahan menuliskan detail soal yang diketahui secara spesifik karena siswa ketinggalan atau tidak memahami simbol fisika dari data yang dicantumkan selama studinya, (4). Kesalahan dalam mengenali dan menafsirkan keseluruhan konteks masalah.

Peneliti menemukan banyak pengaruh yang mempengaruhi kesalahan siswa berdasarkan hasil wawancara. Variabel internal dan eksternal termasuk dalam daftar ini. Motivasi, keinginan, dan kemampuan adalah penyebab internal yang dimaksud. Peneliti menemukan banyak faktor yang mempengaruhi kesalahan siswa berdasarkan hasil wawancara. Variabel internal dan eksternal termasuk dalam daftar ini. Motivasi, keinginan, dan kemampuan adalah penyebab internal yang dimaksud. Selanjutnya, guru dan manusia yang hadir adalah penyebab eksternal yang dimaksud. Aspek ini terlihat pada bagaimana guru menyampaikan konten yang kurang menarik, sehingga siswa kurang memperhatikan apa yang dikatakan guru. Selain itu, siswa suka bermain dengan temannya. Menurut Sari et al. (2013), salah satu cara untuk mengatasi kesalahan siswa dalam pemecahan masalah adalah dengan menginspirasi. Siswa dapat lebih fokus dalam belajar dan mengajukan pertanyaan ketika mereka tidak memahami apapun. Siswa akan lebih tertarik mempelajari lebih banyak tentang konten fisika jika mereka termotivasi untuk menikmati kelas fisika mereka.

Berdasarkan uraian di atas maka dapat disimpulkan bahwa siswa yang berminat pada fisika akan berusaha memahami materi yang diberikan oleh pengajar dan semua materi fisika khususnya materi tentang elastisitas. Selanjutnya siswa harus lebih konsisten mempersiapkannya, tidak hanya saat ada ujian, tapi setiap hari. Siswa kemudian akan mereview pelajaran yang mereka dapatkan di taman kanakkanak. Siswa tidak boleh takut untuk bertanya ketika mereka tidak memahami sesuatu, berusaha menyelesaikan materi pembelajaran, dan bersabar dan akurat setelah mereka menyelesaikan soal. Untuk menginspirasi siswa agar bersemangat belajar dan meningkatkan hasil belajarnya, diperlukan inspirasi baik dari dalam maupun luar kelas. 


\section{Simpulan}

Berdasarkan temuan di atas, dapat disimpulkan bahwa kesalahan yang paling sering dilakukan oleh siswa adalah kesalahan tansformasi, dimana sebagian besar siswa tidak mengerjakan soal sesuai dengan langkah-langkah yang diuraikan dalam soal. Jenis kesalahan yang dilakukan siswa dikelas XI IPA SMA Muhammadiyah Maumere, Kabupaten Sikka dalam menjawab soal materi elastisitas bahan yaitu kesalahan memahami, kesalahan keterampilan proses, transformasi data, dan kesalahan penulisan. Faktor internal dan eksternal merupakan faktor yang memungkinkan siswa melakukan kesalahan dalam menyelesaikan masalah elastisitas. Motivasi, keinginan, dan kemampuan juga merupakan pengaruh internal. Penyebab eksternal, di sisi lain, termasuk guru dan orang lain yang hadir.

\section{References}

Ahliha, S., Mastuang, \& Mahardika, A. I. (2017). Meningkatkan hasil belajar siswa kelas VIII E SMP Negeri 26 Banjarmasin dengan menggunakan metode pemecahan masalah (problem solving) dalam setting pengajaran langsung. Berkala Ilmiah Pendidikan Fisika, 5(1), 118-132.

Clements, M. A. (Ken), \& Ellerton, N. F. (1996). The newman procedure for analysing errors on written mathematical tasks. Retrieved from http://compasstech.com.au/ARNOLD/PAGES/newman.htm

Fitri, E. (2007). Deskripsi kesalahan dalam menyelesaikan soal listrik dinamis pada siswa kelas III SMP Negeri 14 Pontianak. Universitas Tanjungpura Pontianak.

Jha, S. K. (2012). Mathematics performance of primary school students in Assam (India): An analysis using Newman procedure. International Journal of Computer Applications in in Engineering Sciences, II(I), 17-21.

Kim, Hyejin, Sefcik, J. S., \& Bradway, C. (2017). Characteristics of qualitative descriptive studies: A systematic review. Research in Nursing \& Health, 40(1), 23-42.

Letuna, E. Y. (2011). Analisis Kesalahan menurut klasifikasi waston pada siswa dalam mengerjakan soal-soal bentuk akar. Universitas Kristen Satya Wacana.

Mulia, S. A. (2019). PHYLAMENT (Physics Education and Experiment). Jurnal Bina Desa, 1(1), 12-15.

Sari, D. M., Surantoro, \& Ekawati, E. Y. (2013). Analisis kesalahan dalam menyelesaikan soal materi termodinamika pada siswa SMA. Jurnal Materi dan Pembelajaran Fisika (JMPF), 3(2), 33-39.

Seo, Y. (2010). Persentase kelulusan UN di NTT terburuk se-Indonesia.

Suparno, E. (2009). National Manpower Strategy. Jakarta: Kompas. 